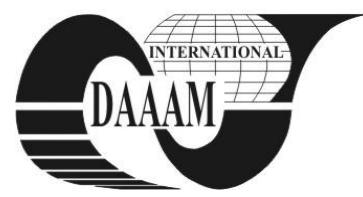

Annals of DAAAM for 2011 \& Proceedings of the 22nd International DAAAM Symposium, Volume 22, No. 1, ISSN 1726-9679 ISBN 978-3-901509-83-4, Editor B. Katalinic, Published by DAAAM International, Vienna, Austria, EU, 2011 Make Harmony between Technology and Nature, and Your Mind will Fly Free as a Bird

\title{
CLOUD COMPUTING: DEFINITION, CHARACTERISTICS, SERVICES AND MODELS
}

\author{
CELAR, S[tipe]; SEREMET, Z[eljko] \& TURIC, M[ili]
}

\begin{abstract}
In the past ten years numerous research experts and cloud computing providers have described and defined cloud computing in own specific way. In this paper we indicate some challenges and warnings regarding cloud computing. Furthermore, we list some important cloud computing definitions and describe its characteristics, service models and deployment models based on the NIST's description as a most comprehensive definition today. In addition a brief analysis of the world's leading CSPs and their service models is given.

Key words: Cloud, Saas, Paas, Iaas, CSP
\end{abstract}

\section{INTRODUCTION}

Cloud computing (CC) is associated with a new paradigm for the provision of computing infrastructure. This paradigm shifts the location of computer infrastructure to the network in order to reduce the costs associated with the management of hardware and software resources. The Cloud is drawing the attention from the Information and Communication Technology (ICT) community, thanks to the appearance of a set of services with common characteristics, provided by important industry players. Nevertheless, CC has not reached its full potential in businesses world. Some reasons, notable even in small markets like Republic of Croatia, are insufficient level of standardization of CC services and its diversity of definitions. This paper gives several recent definitions of $\mathrm{CC}$ and also points out some major challenges.

Paper structure proceeds as follows. In Section 2 we briefly mention CC challenges and warnings mentioned by EU and DoD representatives. In Section 3 some of the world's top CSPs (Cloud Service Provider) and their cloud services are given. Section 4 gives CC definitions overview from the research point of view while Section 5 describes CC key characteristics, services and deployment models using National Institute of Standards and Technology (NIST) definition. Section 6 concludes this paper and describes the future work.

\section{CHALLENGES AND WARNINGS ABOUT CC}

$\mathrm{CC}$ has become so important in this moment that the debate about its technologies is raised on the political level in the European Union. The point is that CC can be applied to various industries, from "raw" IT, to glaze sales and accounting in the cloud. During a speech at the World Economic Forum EU Commissioner Neelie Kroes said that in the context of European digital agenda needs to develop a joint CC strategy. „European Economic Area is a complex system with a large number of participants and countries. Building a unified and stable infrastructure - this is the biggest challenge for the future", said Joseph Reger, the CIO at Fujitsu Technology Solutions. (Skramic, 2011)

This potential is enormous but the way to its realization, unfortunately, is not without serious obstacles. DoD's CIO warned that ,moving information technology to a CC environment without first adopting standardized platforms and virtualized environments would damage information technology systems“(Walker, 2011).

\section{WORLD'S TOP SERVICE PROVIDERS}

World's global CSP's differ in their CC definitions and services they provide. According to $(* * *, 2011)$ the world top providers do not offer all cloud individual services. Based on NIST's service models, these top CSPs can be classified in following groups:

- Infrastructure as a Service (IaaS) providers: Amazon, Rackspace, Joyent, Verizon/Terremark, IBM, CSC, BlueLock, NephoScale

- Platform as a Service (PaaS) providers: Google, Microsoft, Force.com, Spring

- Software as a Service (SaaS) providers: Google Apps, Salesforce.com.

\section{CC DEFINITIONS OVERVIEW}

There are different views of CC. Many researchers gave their own definition and description of $\mathrm{CC}$ for more than 10 years. (Vaquero et al., 2009) defines Clouds as a large pool of easily usable and accessible virtualized resources (such as hardware, development platforms and/or services). These resources can be dynamically re-configured to adjust to a variable load (scale), allowing also for an optimum resource utilization. This pool of resources is typically exploited by a pay-per-use model in which guarantees are offered by the Infrastructure Provider by means of customized Service Level Agreements.

(Vaquero et all, 2009) gives 22 recent CC definitions distinguishing $\mathrm{CC}$ from grid computing while (Bayya et all, 2009) distinguishes CC from grid computing and clustering. According to one of the most cited definition, cloud computing is a type of parallel and distributed system consisting of a collection of inter-connected and virtualized computers that are dynamically provisioned and presented as one or more unified computing resource(s) based on service-level agreements established through negotiation between the service provider and consumers. (Bayya et all, 2009)

\section{NIST'S CLOUD COMPUTING DEFINITION}

The most comprehensive CC description we found in the literature is the description given by NIST. (Mell \& Grance, 2011) According to NIST, CC is a model for enabling ubiquitous, convenient, on-demand network access to a shared pool of configurable computing resources (e.g., networks, servers, storage, applications, and services) that can be rapidly provisioned and released with minimal management effort or service provider interaction.

Cloud model promotes the availability and consists of five key characteristics, the three service delivery models and four deployment models. 


\subsection{Essential Characteristics}

All CC characteristics NIST summarizes into five essential groups:

- On-demand self-service. A consumer can unilaterally provision computing capabilities, such as server time and network storage, as needed automatically without requiring human interaction with each service's provider.

- Broad network access. Capabilities are available over the network and accessed through standard mechanisms that promote use by heterogeneous thin or thick client platforms (e.g., mobile phones, laptops, and PDAs).

- Resource pooling. The provider's computing resources are pooled to serve multiple consumers using a multi-tenant model, with different physical and virtual resources dynamically assigned and reassigned according to consumer demand. There is a sense of location independence in that the customer generally has no control or knowledge over the exact location of the provided resources but may be able to specify location at a higher level of abstraction (e.g., country, state, or datacenter). Examples of resources include storage, processing, memory, network bandwidth, and virtual machines.

- Rapid elasticity. Capabilities can be rapidly and elastically provisioned, in some cases automatically, to quickly scale out, and rapidly released to quickly scale in. To the consumer, the capabilities available for provisioning often appear to be unlimited and can be purchased in any quantity at any time.

- Measured Service. Cloud systems automatically control and optimize resource use by leveraging a metering capability at some level of abstraction appropriate to the type of service (...)

\subsection{Service Models}

Cloud services can be provided to the customers through the following three models:

- Cloud Software as a Service (SaaS). The capability provided to the consumer is to use the provider's applications running on a cloud infrastructure. The applications are accessible from various client devices through a thin client interface such as a web browser (e.g., web-based email). The consumer does not manage or control the underlying cloud infrastructure including network, servers, operating systems, storage, or even individual application capabilities, with the possible exception of limited user-specific application configuration settings.

- Cloud Platform as a Service (PaaS). The capability provided to the consumer is to deploy onto the cloud infrastructure consumer-created or acquired applications created using programming languages and tools supported by the provider. The consumer does not manage or control the underlying cloud infrastructure including network, servers, operating systems, or storage, but has control over the deployed applications and possibly application hosting environment configurations.

- Cloud Infrastructure as a Service (IaaS). The capability provided to the consumer is to provision processing, storage, networks, and other fundamental computing resources where the consumer is able to deploy and run arbitrary software, which can include operating systems and applications. The consumer does not manage or control the underlying cloud infrastructure but has control over operating systems; storage, deployed applications, and possibly limited control of select networking components (e.g., host firewalls).

\subsection{Deployment Models}

The services can be implemented through the following four models:

- Private cloud. The cloud infrastructure is operated solely for an organization. It may be managed by the organization or a third party and may exist on premise or off premise.

- Community cloud. The cloud infrastructure is shared by several organizations and supports a specific community that has shared concerns (e.g., mission, security requirements, policy, and compliance considerations). It may be managed by the organizations or a third party and may exist on premise or off premise.

- Public cloud. The cloud infrastructure is made available to the general public or a large industry group and is owned by an organization selling cloud services.

- Hybrid cloud. The cloud infrastructure is a composition of two or more clouds (private, community, or public) that remain unique entities but are bound together by standardized or proprietary technology that enables data and application portability.

Before NIST' definition was published the Community cloud model was rarely recognized and clearly described by other researchers and CSPs.

\section{CONCLUSION \& FUTURE RESEARCH}

During last decade there was no clear and widely accepted definition of Clouds in the literature that should help to determine the areas of research and explore new application domains for the usage of the Clouds. NIST's novel comprehensive definition should be accepted as a way for standardisation of cloud services for both providers and consumers. Lack of common standards can lead to a complete rejection of computing in the cloud, so it is imperative that all involved parties adopt standardisation initiatives in order to provide CC benefits. In future works we will research cloud services on the Croatian market provided by local and global CSPs, their services and deployment models.

\section{REFERENCES}

Buyya, R.; Shin, Y.C.; Venugopal, S.; Broberg, J. \& Brandic, I. (2009). Cloud computing and emerging IT platforms: Vision, hype, and reality for delivering computing as the 5th utility, FGCS, Vol. 5 (6), June 2009, pp. 599-616

Mell, P. \& Grance, T. (2011). The NIST Definition of Cloud Computing (Draft), National Institute of Standards and Technology Special Publication 800-145 (Draft), Jan. 2011

Škramić, S. (2011). Europa treba zajedničku politiku za cloud computing, Available from: http://www.poslovni.hr/ vijesti/europa-treba-zajednicku-politiku-za-cloudcomputing 179220.aspx, Accessed: 2011-05-12

Vaquero, L.M.; Rodero-Merino, L.; Caceres, J. \& Lindner, M. (2009). A Break in the Clouds: Towards a Cloud Definition, ACM SIGCOMM Computer Communication Review, Vol. 39, N. 1, January 2009, pp. 50-55

Walker, M. (2011). Takai warns against federal cloud adoption without standardized technology, Available from: http://www.fiercegovernmentit.com/story/takai-warnsagainst-federal-cloud-adoption-without-standardizedtechnology/2011-04-25?utm_medium=n1\&utm_source =internal, Accessed: 2011-05-25

*** (2011). Top 10 cloud computing providers of 2011, Available from: http://searchcloudcomputing.techtarget. com/feature/Top-10-cloud-computing-providers-of-2011\# slideshow - Top 10 cloud computing providers of 2011, Accessed: 2011-09-22 